\title{
Armazenamento de sementes de Myracrodruon urundeuva Fr. All. em diferentes embalagens e ambientes
}

\author{
GUEDES, R.S. ${ }^{1 *}$; ALVES, E.U. ${ }^{1}$; BRUNO, R.L.A. ${ }^{1}$; GONÇALVES, E.P. ${ }^{2}$; COSTA, E.G. ${ }^{1}$; MEDEIROS, M.S. ${ }^{1}$ \\ ${ }^{1}$ Universidade Federal da Paraíba, Caixa Posta 02, CEP: 58397-000, Areia-Brasil * roberta_biologa09@yahoo.com.br \\ ${ }^{2}$ Universidade Federal Rural de Pernambuco, Unidade Acadêmica de Garanhuns, Avenida Bom Pastor, s/n, Boa \\ Vista, CEP: 55296-901, Garanhuns-Brasil
}

\begin{abstract}
RESUMO: Myracrodruon urundeuva Fr. All. é uma espécie pertencente à família Anacardiaceae, cuja planta pode ser utilizada como medicinal, na indústria de curtimento de couro, na arborização de ruas e praças, produzindo madeira de grande resistência mecânica. Diante disso, o objetivo deste trabalho foi determinar as melhores condições e períodos de armazenamento para conservação da viabilidade e vigor das sementes de $M$. urundeuva. As embalagens utilizadas para acondicionamento das sementes foram sacos de papel Kraft, algodão e de polietileno transparente, bem como folhas de papel alumínio. Em seguida as sementes foram armazenadas em ambiente natural de laboratório $\left(25 \pm 2^{\circ} \mathrm{C}\right)$, freezer $\left(-20 \pm 2^{\circ} \mathrm{C}\right)$, câmara fria $\left(8 \pm 2^{\circ} \mathrm{C}\right)$ e geladeira $\left(6 \pm 2^{\circ} \mathrm{C}\right)$. Em intervalos pré-determinados $(0,30,60,90,120,150,180,210$ e 240 dias) avaliouse o teor de água das sementes, porcentagem de emergência, índice de velocidade de emergência, comprimento e massa seca de plântulas. No ambiente de laboratório não houve conservação do vigor das sementes de $M$. urundeuva. A melhor condição para conservação de sementes de $M$. urundeuva foi obtida com o acondicionamento em sacos de papel Kraft, pano de algodão, plástico ou papel alumínio e manutenção em geladeira ou freezer, podendo também ser conservadas embaladas em papel ou alumínio, quando estocadas em câmara fria, por 240 dias. Alteração no vigor de sementes dessa espécie é primeiramente identificada pela redução da velocidade de emergência.
\end{abstract}

Palavras-chave: aroeira-do-sertão, emergência, vigor, conservação, planta medicinal

\begin{abstract}
Storage of Myracrodruon urundeuva Fr. All. seeds in different packaging and environments. Myracrodruon urundeuva Fr. All. is a species belonging to the Anacardiaceae family, which can be utilized as a medicinal plant, or in the leather tanning industry, urban afforestation, and the production of wood with great mechanic resistance. The objective of this study was to determine the best conditions and storage periods for preserving the viability and vigor of $M$. urundeuva. Seeds conditioned in bags of Kraft paper, cotton, polyethylene or aluminum foil of mesh polyethylene were stored at room temperature $\left(25 \pm 2^{\circ} \mathrm{C}\right)$, freezer $\left(-20 \pm 2^{\circ} \mathrm{C}\right)$, cold $(8$ $\left.\pm 2^{\circ} \mathrm{C}\right)$ and refrigerator $\left(6 \pm 2^{\circ} \mathrm{C}\right)$. At $30,60,90,120,150,180,210$ and 240 days they were evaluated for seed moisture content, percentage of emergence, emergence speed index (ESI), seedling length and seedling dry matter. In the natural environment of the laboratory, there was no conservation of seed vigor $M$. urundeuva. The best $M$. urundeuva seed conservation condition was obtained with bags of Kraft paper, cotton, polyethylene or aluminum foil of mesh polyethylene in the refrigerator or freezer. M. urundeuva seeds can also be kept in paper bags or aluminum foil when stored in a refrigerated chamber, for 240 days. Seed vigor change in this species is initially identified by decrease in the speed emergence.
\end{abstract}

Key words: Myracrodruon urundeuva (aroeira-do-sertão), emergence, vigor, preservation, medicinal plant

\section{INTRODUÇÃO}

A aroeira-do-sertão (Myracrodruon urundeuva Fr. All) é uma espécie arbórea pertencente à família Anacardiaceae, cuja distribuição natural limita-se à
América do Sul, é nativa do Brasil e mais amplamente distribuída nas regiões Nordeste, Sudeste e CentroOeste (Carmelo-Guerreiro \& Paoli, 1999). A árvore

Recebido para publicação em 11/04/2010

Aceito para publicação em 22/03/2011

Rev. Bras. PI. Med., Botucatu, v.14, n.1, p.68-75, 2012. 
possui madeira dura, elástica, resistente a cupins, de alta densidade e de longa durabilidade, sendo utilizada para diversos fins, especialmente na construção civil (Rizzini, 1995; Lorenzi, 2002). Além disso, é utilizada na arborização de ruas e praças, em curtumes porque a casca da árvore é rica em tanino e também na medicina popular (Albuquerque et al., 2004).

A planta de $M$. urundeuva tem alto valor terapêutico, o qual foi relatado por Goes et al. (2005) em razão de que na entrecasca encontram-se vários componentes fotoquímicos que possuem propriedades antiinflamatórias e cicatrizantes para várias afecções, principalmente ginecológicas e ferimentos cutâneos; anti-histamínicas e analgésicas. Pesquisas com vistas à avaliação científica da eficácia terapêutica têm mostrado evidente efeito antiinflamatório, cicatrizante, antiulcerogênico, antihistamínico, antibradicinina e analgésico (Viana et al., 1997; Rodrigues et al., 2002). Devido ao uso intenso e predatório, a $M$. urundeuva foi incluída na lista oficial do IBAMA como espécie ameaçada de extinção, na categoria vulnerável (IBAMA, 1992).

Por outro lado, vale afirmar que toda semente destinada a semeadura deve ser cuidadosamente beneficiada e conservada, para garantir a manutenção da qualidade fisiológica, até o momento da utilização. Desta forma, a conservação de sementes por períodos mais longos pode ser alcançada com o uso de técnicas adequadas durante o armazenamento, pois possibilita a manutenção da viabilidade. Azevedo et al. (2003) mencionaram que o armazenamento é uma prática fundamental para o controle da qualidade fisiológica da semente, e que a observância deste fator é de extrema importância para que se obtenha a produtividade esperada, mantendo o vigor em nível razoável entre a semeadura e a colheita e, conservando a viabilidade das sementes.

A conservação das sementes pode ser influenciada por fatores como a qualidade inicial teor de água, secagem, ataque de pragas, grau de injúria mecânica, embalagem e condições ambientais de armazenamento, principalmente temperatura e umidade relativa do ar (Carvalho \& Nakagawa, 2000).

$\mathrm{O}$ alto teor de água das sementes, combinado com altas temperaturas, acelera os processos naturais de degeneração dos sistemas biológicos, de maneira que as sementes perdem o vigor rapidamente e algum tempo depois a capacidade de germinação (Azevedo et al., 2003). Para reduzir ao mínimo o processo de deterioração das sementes é necessário que, após a coleta as mesmas sejam armazenadas, adequadamente, podendo assim controlar a deterioração, já que esta não pode ser evitada, como afirmam Villela \& Perez (2004).

Além do controle da temperatura e umidade relativa do ar no ambiente de armazenamento, a preservação da qualidade fisiológica de sementes é influenciada pelo tipo de embalagem utilizada (Ferreira \& Borghetti, 2004), de forma que é necessário avaliar melhor o tipo de embalagem em que as sementes devem ser acondicionadas, pois estas assumem importância relevante na preservação da viabilidade e vigor das sementes. A utilização de embalagens adequadas permite a conservação da qualidade das sementes, propiciando ou não, trocas de vapor d'água com o ar atmosférico (Toledo \& Marcos Filho, 1977). Assim, a escolha da embalagem depende da espécie, do teor de água das sementes, das condições e período de armazenamento (Marcos Filho, 2005), como também devem ser consideradas as condições climáticas sob as quais as sementes serão armazenadas até a próxima semeadura, modalidade de comercialização, disponibilidade e características mecânicas das embalagens (Carvalho \& Nakagawa, 2000).

Em sementes de Sapindus saponaria L. a maior porcentagem e velocidade de emergência das plântulas foram obtidas quando as mesmas foram acondicionadas em sacos de plásticos, de papel ou de algodão e armazenadas durante doze meses em câmara fria (Tonin \& Perez, 2005). Para Jacaratia corumbensis $\mathrm{O}$. Kuntze as embalagens de papel (87\% de germinação) e de plástico (88\% de germinação) proporcionaram boas condições de armazenamento e manutenção da viabilidade da semente por até 180 dias em temperatura ambiente (Cavalcanti \& Resende, 2007).

A umidade de $40 \%$, associada à temperatura de $10^{\circ} \mathrm{C}$, favoreceu a melhor conservação das sementes de Cupania vernalis Cambess por um período de 240 dias, enquanto a elevação da temperatura de armazenamento para $25^{\circ} \mathrm{C}$ reduziu a qualidade fisiológica das mesmas (Vieira et al., 2008). O acondicionamento em lata e a manutenção em geladeira foi a condição adequada para o armazenamento de sementes de Tabebuia roseo-alba e de Tabebuia impetiginosa; as sementes de $T$. impetiginosa também podem ser conservadas embaladas em saco de polietileno, saco de papel Kraft ou lata, quando estocadas em câmara refrigerada (Borba Filho \& Perez, 2009).

O conhecimento sobre a capacidade de armazenamento das sementes permite que sejam adotadas condições adequadas para cada espécie. Desta forma, a pesquisa objetivou determinar as melhores condições (embalagens e ambientes) e períodos de armazenamento para conservação da viabilidade e vigor das sementes de Myracrodruon urundeuva.

\section{MATERIAL E MÉTODO}

A pesquisa foi conduzida no Laboratório de Análise de Sementes (LAS), do Centro de Ciências

Rev. Bras. PI. Med., Botucatu, v.14, n.1, p.68-75, 2012. 
Agrárias, da Universidade Federal da Paraíba, (CCA - UFPB), em Areia - PB, no ano de 2009. As sementes de Myracrodruon urundeuva foram colhidas diretamente de árvores matrizes, no município de Boa Vista - PB. Depois da colheita foram beneficiadas e mantidas em laboratório, à sombra, para secagem natural por cinco dias, em seguida foram homogeneizadas para serem armazenadas.

Condições de armazenamento: as sementes foram acondicionadas em várias embalagens de papel, pano de algodão, plástico e de papel alumínio (sementes envolvidas em quatro partes de $20 \mathrm{~cm}^{2}$ do papel alumínio superpostas e em seguidas enroladas e pressionadas com as mãos, afim de não permitir entrada de ar). Em cada embalagem foi colocada quantidade de sementes necessária para a realização dos testes de cada avaliação posterior (cada período). Assim acondicionadas, as sementes foram armazenadas em ambiente de laboratório $\left( \pm 25^{\circ} \mathrm{C}\right)$, freezer $(-20 \pm$ $\left.2^{\circ} \mathrm{C}\right)$, câmara fria $\left(8 \pm 2^{\circ} \mathrm{C}\right)$ e geladeira $\left(6 \pm 2^{\circ} \mathrm{C}\right)$, por período de 240 dias $(0,30,60,90,120,150$, 180,210 e 240 dias). No início do armazenamento e a cada 30 dias foram retiradas amostras de cada embalagem e ambiente de armazenamento para avaliação das variáveis teor de água, emergência, índice de velocidade de emergência, comprimento e massa seca das plântulas.

\section{Teor de água}

O teor de água das sementes foi determinado com a utilização de quatro subamostras de 25 sementes para cada tratamento, sendo colocadas em estufa a $105 \pm$ $3^{\circ} \mathrm{C}$, por 24 horas, seguindo as recomendações de Brasil (2009).

\section{Teste de emergência}

$O$ teste de emergência foi instalado em casa de crescimento, com quatro repetições de 25 sementes, semeadas em bandejas plásticas com dimensões de 0,40 x 0,40 x 0,11 m, contendo areia lavada e esterilizada, sendo realizadas irrigações diárias para manutenção da umidade do substrato. As contagens foram feitas diariamente, do 6 o até 0210 dia de teste, computando-se as plântulas que emitiram o epicótilo e os resultados foram expressos em porcentagem.

\section{Índice de velocidade de emergência (IVE)}

$O$ índice de velocidade de emergência foi determinado mediante contagem diária do número de plântulas emersas durante 21 dias e, o índice determinado de acordo com a fórmula proposta por Maguire (1962), onde:

$$
I V E=\frac{E_{1}+E_{2}+\ldots+E_{n}}{N_{1}+N_{2}+\ldots+N_{n}}
$$

em que IVE = índice velocidade de emergência; $E_{1}, E_{2}$ e $E_{n}=$ número de plântulas normais emergidas diariamente; $\mathrm{N}_{1}, \mathrm{~N}_{2}$ e $\mathrm{N}_{\mathrm{n}}=$ número de dias decorridos da semeadura a primeira, segunda e última contagem.

\section{Comprimento de plântulas e massa seca}

No final do teste de emergência, as plântulas normais de cada repetição foram medidas com o auxílio de régua graduada em centímetros, sendo os resultados expressos em cm/plântula. As mesmas plântulas da avaliação anterior foram acondicionadas em sacos de papel e levadas a estufa regulada a $65^{\circ} \mathrm{C}$ até obtenção de massa constante (48 horas) e, decorrido esse período, pesadas em balança analítica com precisão de $0,001 \mathrm{~g}$.

\section{Análise estatística e delineamento experimental}

Os tratamentos foram distribuídos em delineamento experimental inteiramente ao acaso, em quatro repetições de 25 sementes, em fatorial 4 x 4 × 9 (4 embalagens, 4 ambientes e 9 períodos de armazenamento). Os dados obtidos foram submetidos à análise de variância e de regressão polinomial.

\section{RESULTADO E DISCUSSÃO}

Pelos dados referentes ao teor de água das sementes de Myracrodruon urundeuva, contidos na Figura 1, observou-se valor inicial em torno de 7,96\%, o qual está de acordo com Figliolia (1988), que classificou as sementes do gênero Myracrodruon como ortodoxas, as quais deveriam ser armazenadas com teor de água em torno de $8 \%$. O teor de água das sementes de $M$. urundeuva, ao longo do armazenamento aumentou em todos os ambientes e embalagens.

Quanto aos ambientes, o maior ganho de teor de água foi em ambiente de laboratório e, com relação às embalagens foi em pano e papel (Figuras $1 \mathrm{~A}, \mathrm{~B}, \mathrm{C}, \mathrm{D})$. As referidas embalagens são permeáveis, de forma que há livre troca de umidade entre as sementes e o meio no qual se encontravam armazenadas. Essas alterações no teor de água das sementes são determinantes no processo de deterioração, uma vez que há aumento na atividade respiratória e, consequentemente, no consumo das reservas. Assim, verifica-se que o teor de água da semente foi mantido em níveis inaceitáveis ao armazenamento em embalagem impermeável. 

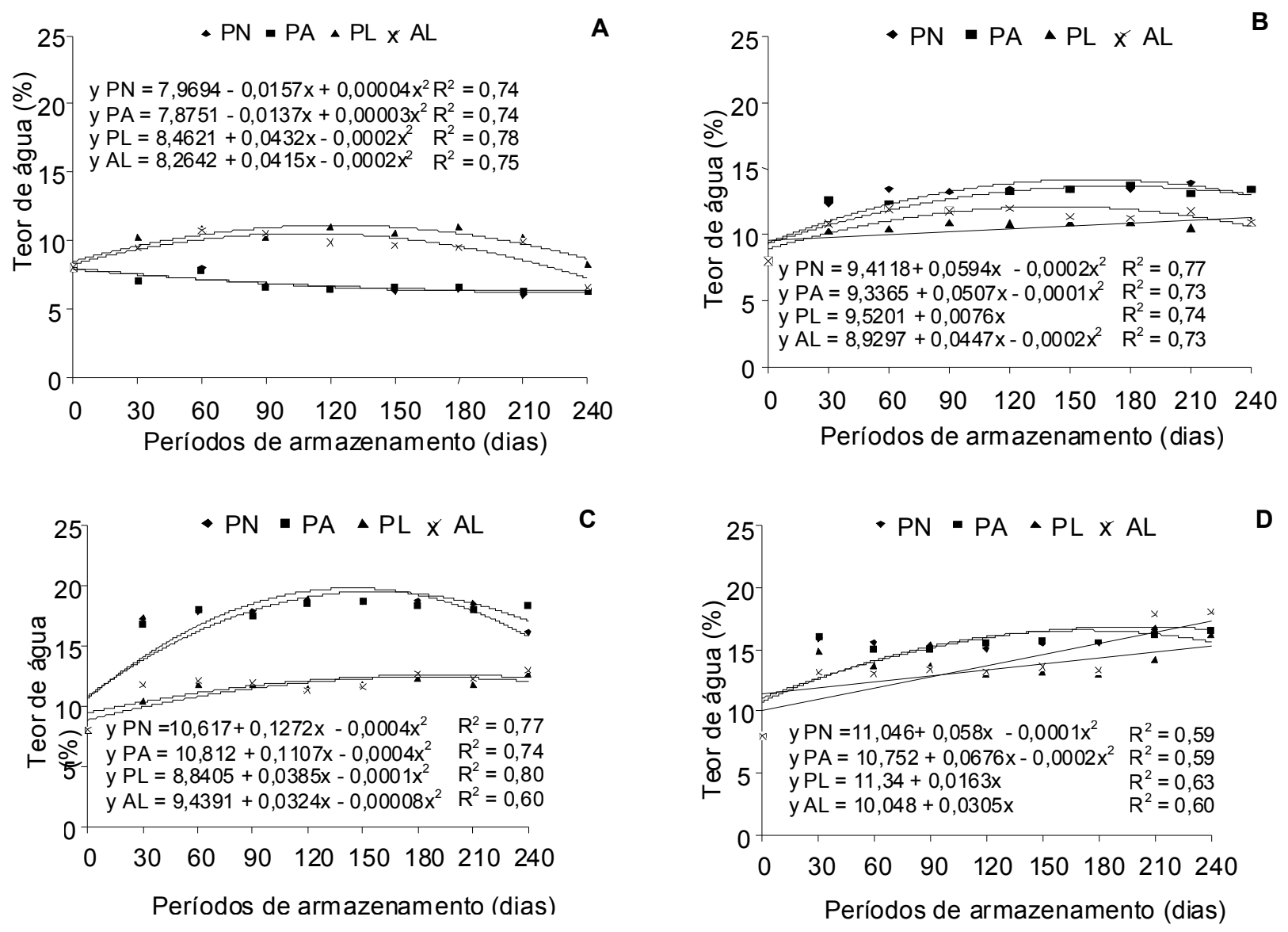

FIGURA 1. Teor de água de sementes de Myracrodruon urundeuva Fr. All. em função do armazenamento em diferentes embalagens e ambientes ( $A$ = geladeira; $B$ = freezer; $C=$ câmara fria; $D=$ laboratório). $P N$ - pano; PA papel; PL - plástico; Al - alumínio.

Nas sementes ortodoxas, o teor de água é um dos fatores mais importantes para a manutenção da viabilidade ao longo do tempo. A redução no teor de água das sementes causa diminuição da atividade metabólica, o que prolonga a viabilidade (Fowler, 2000). Bezerra et al. (2004) constataram que para sementes de Moringa oleifera Lam. armazenadas em ambiente natural, o teor de água decresceu suavemente com o avanço no tempo de armazenamento, enquanto na câmara fria, a variação foi maior, cujos valores no intervalo de zero a seis meses situaram-se no mesmo patamar de $8,8 \mathrm{e}$ $8,6 \%$, caindo para 7,8 e $7,7 \%$ nos períodos subseqüentes (12 e 24 meses). O teor de água de sementes de Tabebuia serratifolia (Vahl.) Nich também sofreu alterações ao longo do armazenamento, independentemente da embalagem (papel e polietileno) e ambiente (câmara, laboratório e geladeira) (Souza et al., 2005).

No período inicial de armazenamento das sementes de $M$. urundeuva registrou-se um porcentual de emergência de plântulas em torno de 85\% (Figuras 2A, B, C, D), o qual reduziu em todos os ambientes e embalagens ao longo do armazenamento, sendo a redução mais drástica no ambiente de laboratório, no qual se verificou um porcentual de emergência aos 240 dias de armazenamento de $9 \%$ - pano; $9 \%$ - papel; $2 \%$ - plástico e $5 \%$ alumínio (Figura 2D).

Tais resultados devem-se, provavelmente, as oscilações de umidade e temperatura do ambiente, aliado ao aumento do teor de água das sementes, o que proporcionou aumento na respiração e, consequentemente, maior consumo nas reservas da semente. Teófilo et al. (2004) mencionaram que nas sementes de $M$. urundeuva acondicionadas em saco de papel sob condições ambientais há redução drástica da porcentagem de germinação ao longo do tempo de armazenamento, atingindo o porcentual de $0 \%$ a partir dos 9 meses. Caldeira \& Perez (2008) constataram que os diásporos de $M$. urundeuva mantidos em ambiente de sala perderam rapidamente a viabilidade e o vigor iniciais, após seis meses de armazenamento.

O armazenamento e a refrigeração são importantes para minimizar a redução da emergência das plântulas de $M$. urundeuva, pois se observou que 

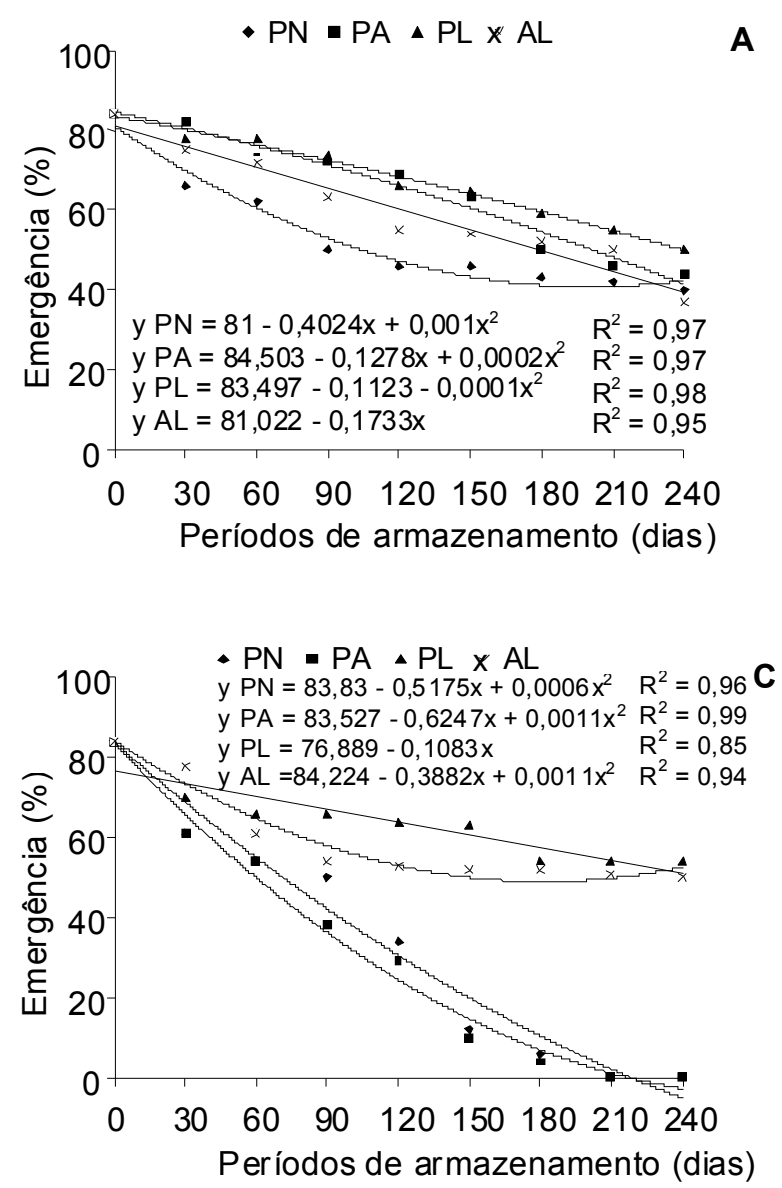
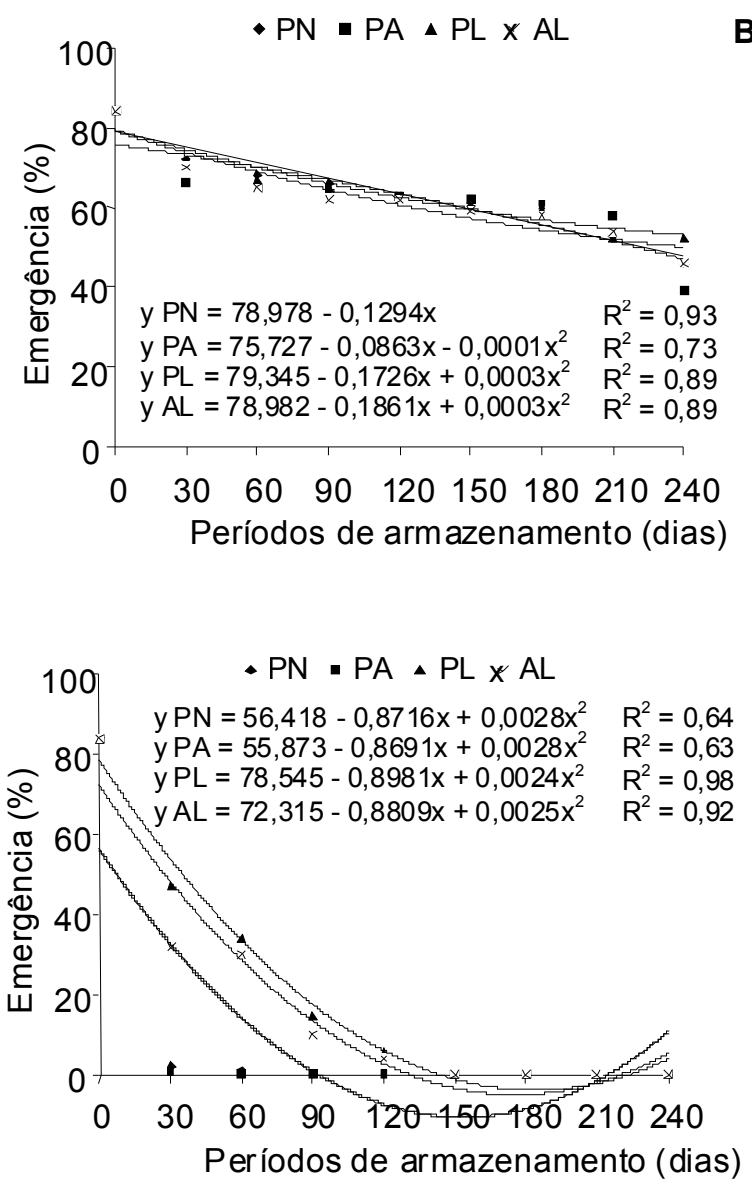

FIGURA 2. Emergência de plântulas de Myracrodruon urundeuva Fr. All. em função do armazenamento em diferentes embalagens e ambientes ( $A$ = geladeira; $B$ = freezer; $C$ = câmara fria; $D$ = laboratório). $P N$ - pano; PA - papel; $P L$ plástico; Al - alumínio.

a porcentagem de emergência diminuiu lentamente com os períodos de armazenamento sob ambiente refrigerado, sendo que na geladeira houve maior conservação das sementes, atingindo $65 \%$ (papel) e $62 \%$ (plástico) aos 240 dias de armazenamento (Figura 2A). Aos 240 dias de armazenamento em freezer, as sementes de $M$. urundeuva atingiram $48,60,55$ e $51 \%$ de emergência nas embalagens de pano, papel, plástico e alumínio, respectivamente (Figura 2B). Para as sementes armazenadas em câmara fria (Figura 2C) verificou-se que aos 210 dias não houve mais emergência de plântulas provenientes de sementes acondicionadas em embalagens de pano e papel, enquanto que para aquelas acondicionadas nas embalagens de plástico e alumínio a emergência foi de 50 e $54 \%$, respectivamente.

A emergência de plântulas de Tabebuia serratifolia (Vahl.) Nich não foi influenciada pelos ambientes de armazenamento (câmara, laboratório e geladeira) e nem pelas embalagens (papel e polietileno) utilizadas (Souza et al., 2005). A porcentagem de emergência de plântulas de Jacaranda cuspidifolia Mart. oriundas de sementes armazenadas sob refrigeração foi maior do que as armazenadas na temperatura ambiente, em todos os períodos de armazenamento (Scalon et al., 2006). Para as sementes de Myracodruon urundeuva Fr. All., Souza et al. (2007) indicaram o ambiente de refrigeração (câmara fria) para conservação das sementes, as quais atingiram $58 \%$ de germinação aos 180 dias.

O vigor, determinado pelo índice de velocidade de emergência (IVE) também reduziu em todos os ambientes e embalagens, sendo mais afetado do que a emergência (Figuras 3A, B, C). A redução foi mais acentuada em ambiente de laboratório, local onde as condições climáticas não são controladas (Figura 3D). Mais uma vez observase que as oscilações das condições climáticas desse ambiente de armazenamento foram cruciais para a perda do vigor das sementes em menor período. 

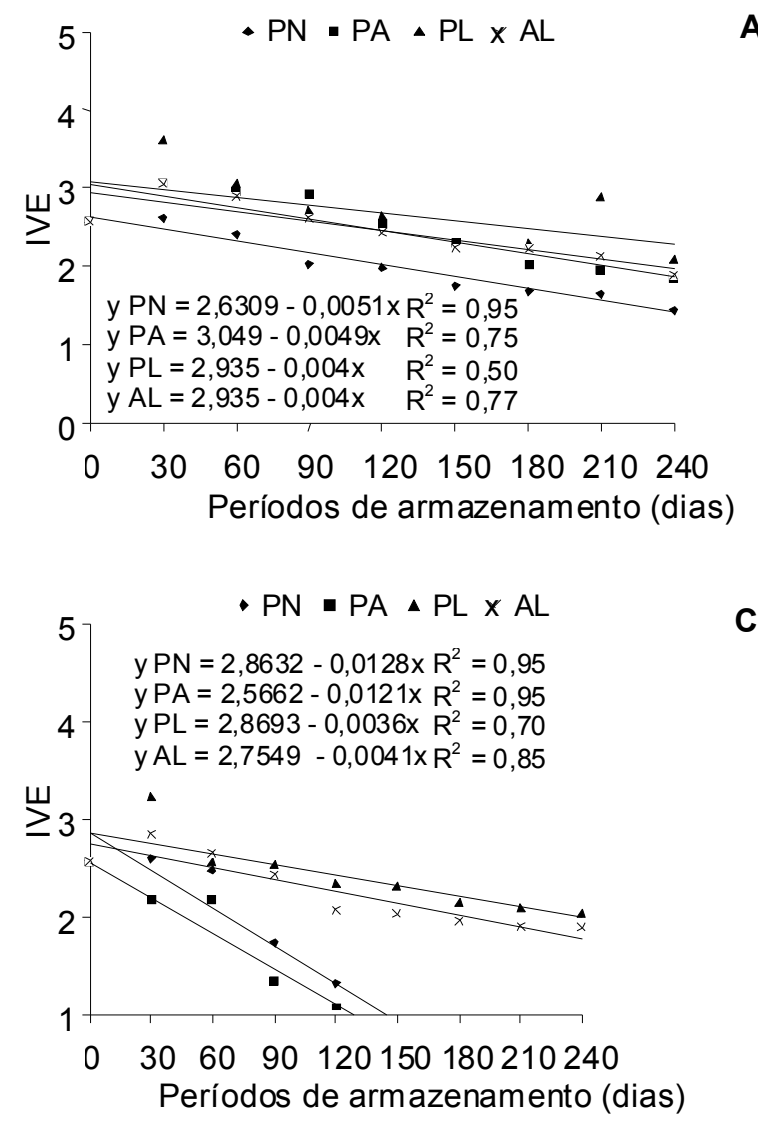

A

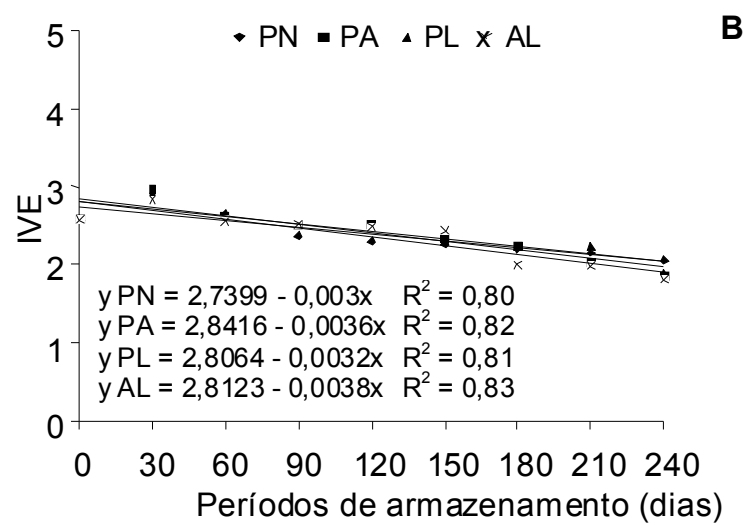

C

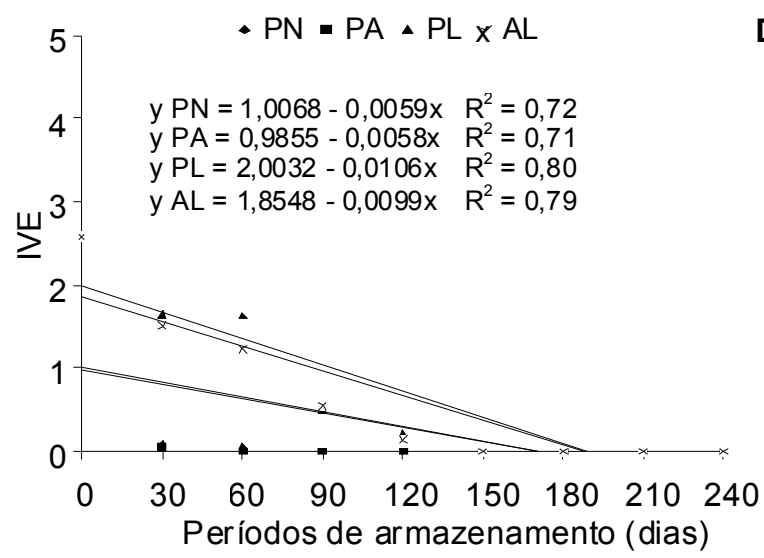

D

FIGURA 3. Índice de velocidade de emergência de plântulas de Myracrodruon urundeuva Fr. All. em função do armazenamento em diferentes embalagens e ambientes ( $\mathrm{A}=$ geladeira; $\mathrm{B}=$ freezer; $\mathrm{C}=$ câmara fria; $\mathrm{D}=$ laboratório). PN - pano, PA - papel, PL - plástico e Al - alumínio.

A perda de viabilidade e redução drástica da velocidade de germinação das sementes de Myracodruon urundeuva Fr. All., em ambiente natural, também foi verificada por Teófilo et al. (2004). Por ser uma espécie cujas sementes são oleaginosas, o poder germinativo é perdido bem mais rápido, principalmente, quando armazenadas em ambiente natural e acondicionadas em embalagens permeáveis. A redução do vigor pode decorrer da baixa estabilidade química dos lipídios, uma vez que elevação moderada da temperatura, como consequência do processo respiratório é suficiente para a decomposição dos lipídios e elevação da taxa de deterioração e, por esse motivo, as sementes de $M$. urundeuva devem ser armazenadas com teor de água inferior ao recomendado para as amiláceas (Marcos Filho, 2005), ou seja, entre 8 e $10 \%$.

A velocidade de emergência de plântulas de Tabebuia serratifolia (Vahl.) Nich reduziu em função dos ambientes de armazenamento (câmara, laboratório e geladeira) e embalagens (papel e polietileno) utilizadas (Souza et al., 2005). Para Jacaranda cuspidifolia Mart. a velocidade de emergência de plântulas foi significativamente maior quando originadas de sementes armazenadas sob refrigeração (Scalon et al., 2006).

Pelos dados da Figura 4 observa-se que nos ambientes sob condições controladas (geladeira, freezer e câmara) o comprimento de plântulas de M. urundeuva apresentou pequenas reduções, mostrando-se mais vigorosas em ambas as embalagens (Figuras 4A, B, C). Entretanto, nas condições de laboratório a perda de vigor foi mais significativa e drástica (Figura 4D). Diante desses resultados constata-se que sob condições de laboratório a deterioração das sementes foi muito drástica, devido ao fato de ocorrer oscilações na temperatura e umidade relativa do ar.

Nos ambientes de geladeira (Figura 4A) e freezer (Figura 4B) o vigor das sementes de $M$. urundeuva reduziu linearmente em todas as embalagens testadas, sendo que aos 240 dias de armazenamento as plântulas tinham $11,9 \mathrm{~cm}$ - pano; 

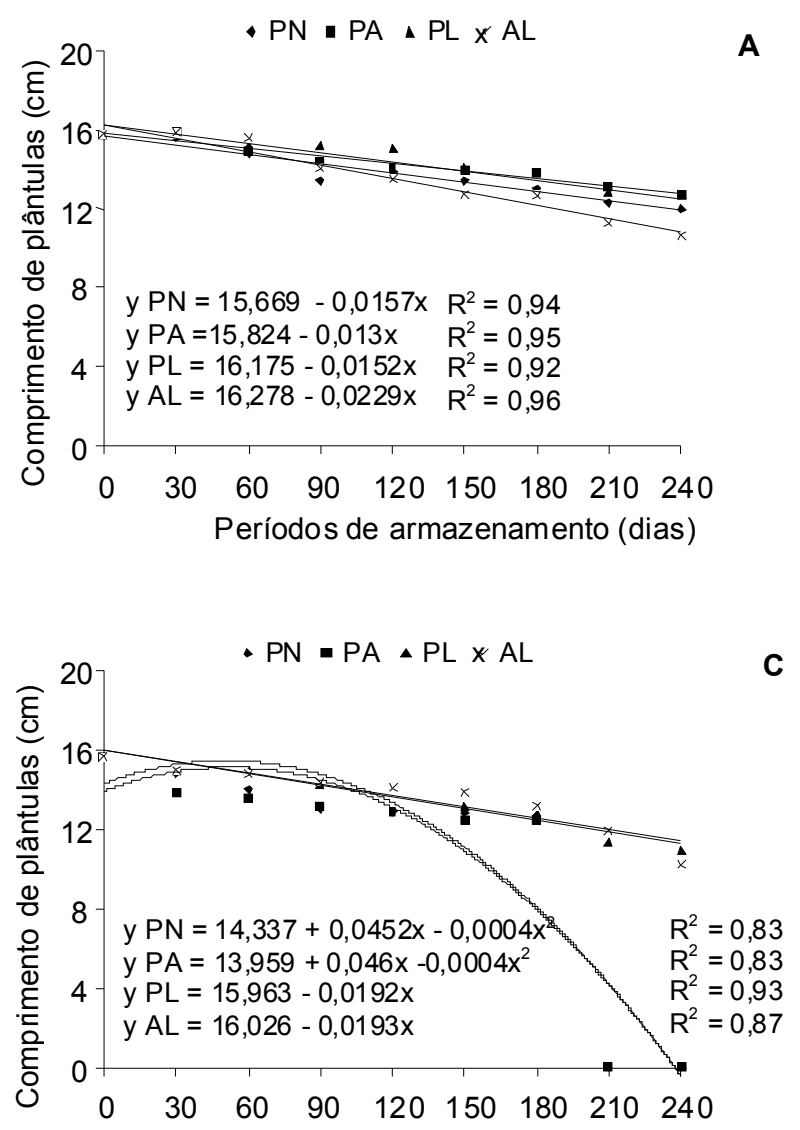

Períodos de armazenamento (dias)

A
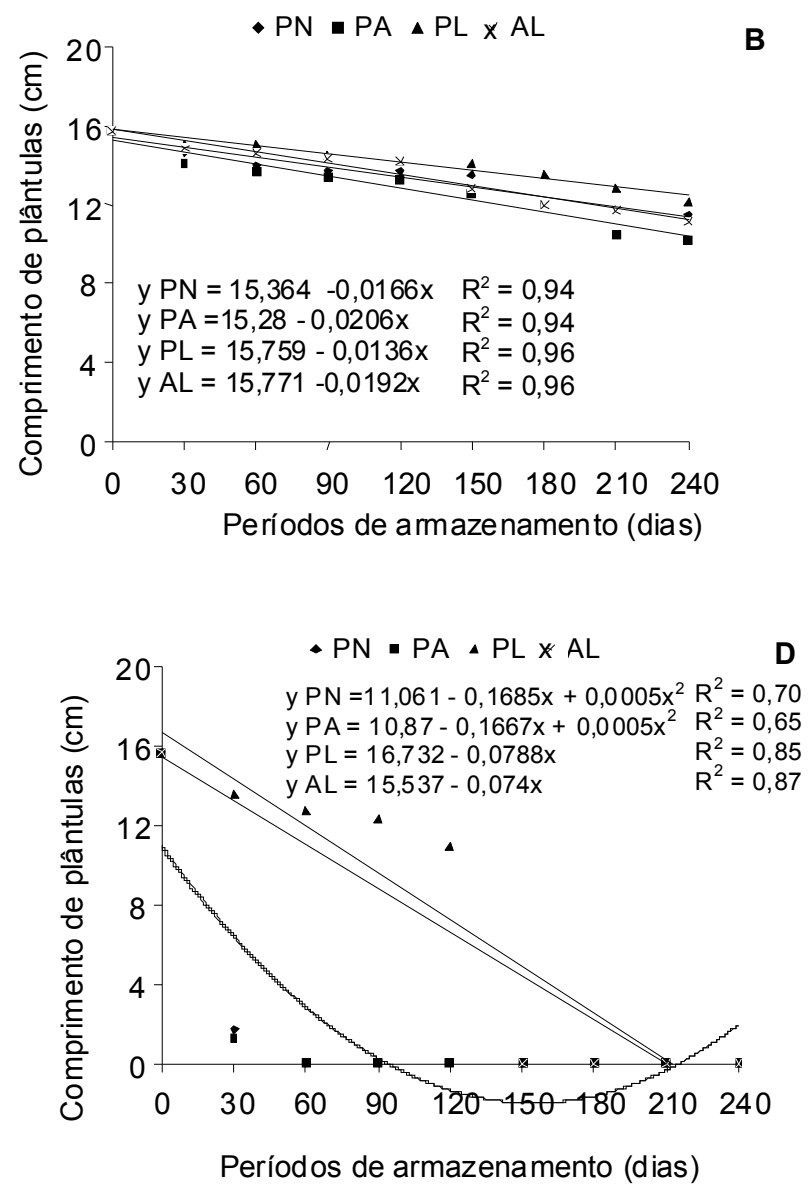

FIGURA 4. Comprimento de plântulas de Myracrodruon urundeuva Fr. All. em função do armazenamento em diferentes embalagens e ambientes $(A=$ geladeira; $B=$ freezer; $C$ = câmara fria; $D=$ laboratório). $P N$ - pano, $P L$ papel, PT - plástico, Al - alumínio.

$12,7 \mathrm{~cm}$ - papel; $12,5 \mathrm{~cm}$ - plástico; $10,7 \mathrm{~cm}$ - alumínio e no ambiente de freezer $11,3 \mathrm{~cm}$ - pano; $10,3 \mathrm{~cm}$ papel; $12,4 \mathrm{~cm}$ - plástico; $11,16 \mathrm{~cm}$. No ambiente de câmara fria houve conservação do vigor das sementes apenas nas embalagens de plástico e alumínio, constatando-se comprimentos nulos nas embalagens de pano e papel aos 240 dias de armazenamento (Figura 4C).

$\mathrm{Na}$ Figura 4D encontram-se os dados referentes ao comprimento das plântulas de $M$. urundeuva oriundas de sementes acondicionadas em diferentes embalagens e armazenadas em ambiente natural de laboratório, o qual foi responsável pela perda de vigor mais significativa, em ambas as embalagens, sendo registrado valores nulos a partir dos 210 dias de armazenamento. Em condições de ambiente, a umidade presente no ar pode promover o reinício das atividades do embrião, caso o oxigênio e a temperatura seja suficiente para que tal processo aconteça, acelerando assim a perda do vigor das sementes (Toledo \& Marcos Filho, 1977).
As sementes dos tratamentos cujas plântulas se encontravam com os maiores valores médios de comprimento ou das partes destas foram considerados por Vieira \& Carvalho (1994) como mais vigorosas. Desse modo, as sementes vigorosas originam plântulas com maior taxa de crescimento, em razão da maior capacidade de translocação de suas reservas e maior assimilação destas pelo eixo embrionário.

O comprimento da raiz primária e da parte aérea de plântulas de Parkia pendula Benth. ex. Walp. oriundas de sementes acondicionadas em embalagens de alumínio, plástico e papel e armazenadas em câmara refrigerada e ambiente natural reduziu a partir do terceiro mês (Rosseto, 2006). Nas plântulas de Tabebuia serratifolia (Vahl.) Nich o comprimento reduziu em função dos ambientes de armazenamento (câmara, laboratório e geladeira) e embalagens (papel e polietileno), sendo mais drástica em condições ambientais de laboratório, em ambas embalagens (Souza et al., 2005). 


\section{CONCLUSÃO}

O acondicionamento em papel, pano de algodão, plástico ou papel alumínio e manutenção em geladeira ou freezer é uma condição adequada para o armazenamento de sementes de Myracrodruon urundeuva, por um período de 240 dias; estas também podem ser conservadas embaladas em papel ou alumínio, quando estocadas em câmara fria.

Alteração no vigor de sementes dessa espécie é primeiramente identificada pela redução da velocidade de emergência.

\section{REFERÊNCIA}

AZEVEDO, M.R.Q.A. et al. Influência das embalagens e condições de armazenamento no vigor de sementes de gergelim. Revista Brasileira de Engenharia Agrícola e Ambiental, v.7, n.3, p. 519-24, 2003.

BEZERRA, A.M.E. et al. Germinação de sementes e desenvolvimento de plântulas de moringa (Moringa oleifera Lam.) em função do peso de sementes e do tipo de substrato. Horticultura Brasileira, v.22, n.2, p.2959, 2004.

BRASIL. Ministério da Agricultura, Pecuária e Abastecimento. Regras para análise de sementes. Brasília, DF: Mapa/ACS, 2009. 399p.

CALDEIRA, S.F.; PEREZ, S.C.J.G.A. Qualidade de diásporos de Myracrodruon urundeuva Fr. All. armazenados sob diferentes condições. Revista Brasileira de Sementes, v.30, n.3, p.185-94, 2008.

CARMELLO-GUERREIRO, S.M.; PAOLI, A.A.S. Aspectos morfológicos anatômicos da semente de aroeira (Myracrodruon urundeuva Fr. Allem. - Anacardiaceae), com notas sobre paquicalaza. Revista Brasileira de Sementes, v.21, n.1, p.222-8, 1999.

CARVALHO, N.M.; NAKAGAWA, J. Sementes: ciência, tecnologia e produção. 4.ed. Jaboticabal: FUNEP, 2000. 588p.

CAVALCANTI, N.B.; RESENDE, G.M. Conservação de sementes de mamãozinho-de-veado (Jacaratia corumbensis O. Kuntze - Caricaceae). Caatinga, v.20, n.2, p.68-72, 2007.

FERREIRA, A.G.; BORGHETTI, F. Germinação: do básico ao aplicado. Porto Alegre: Artmed, 2004. 323p.

FIGLIOLIA, M.B. Conservação de sementes de essências florestais. São Paulo: Instituto Florestal, 1988. 18p. (Boletim Técnico, 42).

FOWLER, J.A.P. Superação de dormência e armazenamento de sementes de espécies florestais. In: GALVÃO, A.P.M. (Org.) Reflorestamento de propriedades rurais para fins produtivos e ambientais: um guia para ações municipais e regionais. Brasília: Embrapa Comunicação para Transferência de Tecnologia; Colombo: Embrapa Florestas, 2000. p.7799.

GOES, A.C.A.M. et al. Análise histological da cicatrização da anastomose colônica, em ratos, sob ação de enema de Aroeira-do sertão (Myracrodruon urundeuva Fr. All.) a 10\%. Acta Cirúrgica Brasileira, v.20, n.2, p. 149-51, 2005. IBAMA. Instituto Brasileiro de Meio Ambiente e dos
Recursos Naturais Renováveis. Lista oficial de espécies da flora brasileira ameaçada de extinção. Portaria no 37-N de 3 de abril de 1992. Disponível em: <http://www.ibama.gov.br>. Acesso em: dez. 2008.

LORENZI, H. Árvores brasileiras: manual de identificação e cultivo de plantas arbóreas nativas do Brasil. 2.ed. Nova Odessa: Plantarum. 2002. 368p.

MAGUIRE, J.D. Speed of germination aid in selection and evaluation for seeding emergence and vigor. Crop Science, v.2, n.2, p.76-7, 1962.

MARCOS FILHO, J. Fisiologia de sementes de plantas cultivadas. Piracicaba: FEALQ, 2005. 495p.

RIZZINI, C.T. Árvores e madeiras úteis do Brasil: manual de dendrologia brasileira. 2.ed. São Paulo: Edgard Blucher, 1995. 296p.

RODRIGUES, L.V. et al. Morphologic and morphometric analyses of acetic acid-induced colitis in rats after treatment with enemas from Myracrodruon urundeuva Fr. All. (Aroeira-do-Sertão). Phytotherapy Research, v.16, n.3, p.267-72, 2002.

ROSSETO, J. Morfologia, germinação, armazenamento e sanidade de sementes de Parkia pendula (Willd.) Benth. ex Walp. - Fabaceae. 2006. 102p. Dissertação (Mestrado em Agricultura Tropical) - Universidade Federal de Mato Grosso, Faculdade de Agronomia e Medicina Veterinária, Cuiabá.

SCALON, S.P.Q. et al. Armazenamento e tratamentos prégerminativos em sementes de jacarandá (Jacaranda cuspidifolia Mart.). Revista Árvore, v.30, n.2, p.179-85, 2006.

SOUZA, S.C.A. et al. Conservação de sementes de Myracodruon urundeuva Freire Allemão (Anacardiaceae) em diferentes condições de armazenamento. Revista Brasileira de Biociências, v.5, supl. 2, p.1140-2, 2007. SOUZA, V.C. et al. Vigor de sementes armazenadas de ipê-amarelo Tabebuia serratifolia (Vahl.) Nich. Revista Árvore, v.29, n.6, p.833-41, 2005.

TEÓFILO, E.M. et al. Qualidade fisiológica de sementes de aroeira (Myracrodruon urundeuva) em função do tipo de embalagem, ambiente e tempo de armazenamento. Revista Ciência Agronômica, v.35, n.2, p.371-6, 2004. TOLEDO, F.F.; MARCOS FILHO, J. Manual de sementes: tecnologia da produção. São Paulo: Agronômica Ceres, 1977. 224p.

TONIN, G.A.; PEREZ, S.C.J.G.A. Qualidade fisiológica de sementes de Ocotea porosa (Nees et Martius ex. Nees) após diferentes condições de armazenamento e semeadura. Revista Brasileira de Sementes, v.28, n.2, p.26-33, 2006.

VIANA, G.S.B. et al. Analgesic and antiinflammatory effects of the tannine fraction from Myracrodruon urundeuva Fr. All. Phytotherapy Research, v.11, n.2, p.118-22, 1997. VIEIRA, C.V. et al. Germinação e armazenamento de sementes de camboatã (Cupania vernalis Cambess.) Sapindaceae. Ciência e Agrotecnologia, v.32, n.2, p.4449, 2008.

VIEIRA, R.D.; CARVALHO, N.M. Testes de vigor em sementes. Jaboticabal - SP: FUNEP/UNESP, 1994. 164p. VILLELA, F.A.; PEREZ, W.B. Tecnologia de sementes coleta, beneficiamento e armazenamento. In: FERREIRA,. A.G.; BORGHETTI, F. (Coord.). Germinação - do básico ao aplicado, Porto Alegre: Artmed, 2004. p.265-80. 